\title{
Genetic variation within and between populations of Pinus sylvestris L. (Scots pine) for susceptibility to Melampsora pinitorqua Rostr. (pine twist rust)
}

\author{
CHRISTINE QUENCEZ \& CATHERINE BASTIEN* \\ Unité Amélioration, Génétique, et Physiologie forestières, INRA, BP 20619, Ardon 45166 Olivet Cedex, France
}

\begin{abstract}
The genetic variability of Scots pine (Pinus sylvestris L.) for twist rust susceptibility and the consequences for genetic improvement of the species were evaluated after artificial inoculation of 1 -year-old seedlings in greenhouse tests. Wind-pollinated progenies, factorial and incomplete diallel mating designs were used to compare two natural populations of Scots pine (Haguenau, France, and Taborz, Poland) and their hybrids (Haguenau $\times$ Taborz). Families from Taborz were significantly $(P<0.001)$ less susceptible to twist rust than those from Haguenau. Inter-population hybrids were as susceptible as the Haguenau population. No clear relationship between severity of infection, shoot length and phenological stage at time of inoculation was observed in intra- and interpopulation crosses. Differences observed between the two natural populations for their response to twist rust are suggested to be the consequence of local adaptation simultaneously for climatic conditions and pathogen pressure. Within each of the two populations, the effects of general combining abilities (GCA) for rust susceptibility were predominant, although estimation of individual heritabilities remained at a moderate level (0.30-0.54). In interpopulation crosses, GCA effects of Haguenau and Taborz populations were still predominant. Moreover, hybrid performance could be predicted with confidence based on the intrapopulation GCA values of parents. Genetic gain on twist rust resistance could be achieved quickly through intrapopulation mass or backward selection based on windpollinated progeny tests.
\end{abstract}

Keywords: combining ability, genetic variation, rust susceptibility, Scots pine, twist rust.

\section{Introduction}

Pinus sylvestris has an extensive natural distribution that spreads longitudinally over a distance of about $14000 \mathrm{~km}$ across the Northern Hemisphere, throughout much of Eurasia (Boratynski, 1991). The species shows great genetic variability for several traits and, thus, can adapt to diverse environments. Because of its large natural range, Scots pine is host to many different pests (Stephan, 1991).

Twist rust, caused by Melampsora pinitorqua Rostr., is an economically important rust of pines in European countries, particularly in Scandinavia, Italy, Poland and France (Klingstrom, 1963; Desprez-Loustau, 1986; Siwecki \& Chojnacki, 1989). This host-alternating rust produces its pycnioaecial stage on several species of

*Correspondence. E-mail: catherine.bastien@orleans.inra.fr
European pines (P. pinea L., P. sylvestris L., P. nigra Arn., $P$. pinaster Ait. and $P$. halepensis Mill.) and its uredial and telial stages on Populus section. This rust infects the unlignified elongating pine shoots; infected shoots develop a resin-soaked canker resulting sometimes in the death of the leader shoot and in further development of numerous concurrent stems. Seedlings and young trees, up to 5-10 years in age, are especially prone to attack. Moreover, pines are susceptible to infections for a short period during shoot elongation (Kurkela, 1973; Desprez-Loustau \& Dupuis, 1994).

In France, gains in the genetic quality of Scots pine plantations are expected from gradually improving two large breeding populations created from two natural populations with complementary adaptive and wood production performances. Trees from Scots pine plantations at Haguenau, France, the most southwesterly population of the range at low elevation, are appreciated 
for their superior height and diameter growth despite bad stem form and relative susceptibility to several pests. Trees from Scots pine plantations at Taborz, north-eastern Poland, have proven a good compromise in France between volume production, stem quality and insect resistance. In both populations, a description of genetic variability for twist rust susceptibility is now needed to identify the best intrapopulation breeding strategies to achieve simultaneous genetic gain on this new selection goal.

The available information on the quantitative genetics of pine twist rust resistance is far from complete. Martinsson (1987) found significant genetic variation in susceptibility to pine twist rust between full-sib families of Scots pine under artificial conditions, and concluded that there was a real possibility of making genetic selections among 1-year-old seedlings to improve the general combining ability for twist rust resistance. Under natural conditions and for the same pathosystem, Andersson \& Danell (1997) showed some population differentiation over Scandinavia but confirmed the presence of large within-population variation. Decomposition of genetic variance into additive and nonadditive statistical effects has been performed only in Pinus pinaster by Baradat \& Desprez-Loustau (1997). In this species, additive genetic variability is of great importance even if small dominance effects were detected. The potential benefits of interpopulation hybridization have rarely been exploited to improve forest tree resistance to diseases (Old et al., 1986; Harfouche et al., 1995). The combination of complementary performances of parent populations are expected to result in more durable resistance to disease in Haguenau $\times$ Taborz crosses, in addition to positive heterosis.

The experiment presented here was designed to provide genetic information about intra- and interpopulation hybrids of Scots pine for their susceptibility to twist rust. The specific objectives were:

1 to compare the present level of susceptibility and potential improvement through intrapopulation recurrent selection of two breeding populations of different geographical origin,

2 to compare general (GCA) and specific combining abilities (SCA) of a fixed set of parents in intra- and interpopulation crosses in order to define the best breeding strategy for the production of superior hybrid combinations.

Because pine susceptibility to rust may be influenced by the amount of susceptible tissues (Hollis et al., 1975; Desprez-Loustau \& Wagner, 1997) and phenological stage (Desprez-Loustau \& Dupuis, 1994), shoot length and phenology were included in the study to estimate genetic variation for true defence mechanisms.

\section{Materials and methods}

Inoculum source

Aspen (Populus tremula) leaves, with teliospores of Melampsora pinitorqua, were collected near infected pines in Brinon-sur-Sauldre forest $\left(47^{\circ} 30^{\prime} \mathrm{N}, 2^{\circ} 09^{\prime} \mathrm{E}\right.$, France) during the period of teliospore maturation in April 1998 and 1999. In order to avoid the germination of teliospores, leaves were kept in a dry place prior to the inoculation of 1-year-old seedlings.

\section{Host material}

All genotypes that constitute the base material for operational tree breeding were initially selected in European native stands. The French genotypes were native to north-eastern France - Haguenau $\left(48^{\circ} 49^{\prime} \mathrm{N}\right.$, $\left.7^{\circ} 47^{\prime} \mathrm{E}\right)$ - and the Polish genotypes came from northeastern Poland - Taborz $\left(19^{\circ} 59^{\prime} \mathrm{E}, 53^{\circ} 47^{\prime} \mathrm{N}\right)$. Trees were chosen aged 80-100 years based on phenotypic performance: volume production, stem form and wood density (only for Haguenau). Scions were obtained from these selections to produce grafted trees, which were represented in two breeding populations, in clonal archives.

\section{Greenhouse experiment}

Two series of tests with different genotypes of Haguenau and Taborz populations were raised to investigate genetic components involved in twist rust quantitative resistance. Progeny tests were established in randomized complete block designs with eight and five blocks in 1997 (test A) and 1998 (test B), respectively. Each family was represented in row-plots of six seedlings in each block. Because they limit technical errors, multiple tree plots were used more frequently than other type of experimental design in early genetic evaluation of forest trees (Dinkins, 1992). Seeds were germinated and grown in individual plastic pots containing sand-vermiculite mixture under greenhouse conditions.

Table 1 summarizes all material tested in the two series (including seeds of wind-pollinated progenies (WP) and full-sib families (FS) from Haguenau and Taborz populations and full-sib families (FS) from Haguenau $\times$ Taborz crosses). WP families of Taborz origin were collected in natural stands in Poland and those from Haguenau were collected in natural stands when it was possible or in seed orchards from the same population. In test A, 10 FS families extracted from a $6 \times 6$ half-diallel represented the intrapopulation crosses from Taborz origin. 


\begin{tabular}{|c|c|c|}
\hline & Test A & Test B \\
\hline WP families & 20 & 6 \\
\hline From Haguenau & 9 & 5 \\
\hline From Taborz & 11 & 1 \\
\hline Intrapopulation Haguenau & $3 \hat{\jmath} \times 3+(9 \mathrm{FS})$ & $7 \hat{o} \times 4$ 우 $(23 \mathrm{FS})$ \\
\hline Intrapopulation Taborz & $30^{\hat{1}} \times 5$ 우 (10 FS) & $6 \hat{\jmath} \times 4$ 우 $(16 \mathrm{FS})$ \\
\hline $\begin{array}{l}\text { Interpopulation } \\
\quad \text { Haguenau } \times \text { Taborz }\end{array}$ & $6 \widehat{0} \times 6$ 우 (21 FS) & $5 \hat{\jmath} \times 5$ 우 $(16 \mathrm{FS})$ \\
\hline No. of seedlings & 2171 & 2010 \\
\hline
\end{tabular}

Table 1 Number of male ( $\left.0^{\wedge}\right)$ and female (†) genotypes, wind-pollinated (WP) and full-sib (FS) families included in the two experiments (A and B). The numbers of tested full-sib families (FS) are given in parentheses

\section{Evaluation of twist rust susceptibility in 1-year-old seedlings}

We adapted the method developed in earlier studies by Martinsson (1980) for the artificial inoculation of large quantity of young pines. All boxes containing the 1 -year-old seedlings were put in a trolley topped at 40 $\mathrm{cm}$ with wire netting. The young pines were inoculated simultaneously with the same batch of inoculum when the major parts of the seedlings were in the susceptible growth stage, observed between bud-scale disjunction and needle emergence (Desprez-Loustau \& Wagner, 1997). Moist aspen leaves were placed uniformly on the netting to allow basidiospore discharge on the seedlings. The aspen leaves were maintained over the pine seedlings during one week under moist filter paper. High moisture conditions were maintained by use of a water mist system and an airing system ensured favourable temperatures within the greenhouse.

The severity of symptoms was evaluated on a $0-3$ scale, combining the number and dispersion of aecia along the leader shoot $(\mathrm{Ndc}), 15$ days after the inoculation of seedlings in May 1998 (Ndc98) and 1999 (Ndc99): 0, seedling showing no rust symptoms; 1, 1-5 aecia scattered along the leader shoot; 2 , more than 5 aecia confined in the same area of the leader shoot; 3 , numerous united aecia. The percentage of leader shoot surface covered by pine twist rust symptoms (Psi) was evaluated on a 0-4 scale 15 days after inoculation in 1998 (Psi98) and in 1999 (Psi99): 0, seedling showing no rust symptoms; 1 , aecia covering less than $25 \%$ of the leader shoot surface; 2 , aecia covering between $25 \%$ and $50 \%$ of the leader shoot surface; 3 , aecia covering between $50 \%$ and $75 \%$ of the leader shoot surface; 4 , aecia covering more than $75 \%$ of the leader shoot surface.

\section{Assessment of growth and phenological characters}

The length of the leader shoot (SL, mm) at inoculation was assessed in 1998 (SL98) in test A and in 1999 (SL99) in test B. This growth trait allowed us to estimate the influence of susceptible shoot length available at time of seedling inoculation on twist rust susceptibility.

Pine shoots show different degrees of susceptibility to $M$. pinitorqua according to their phenological stage with the maximum susceptibility observed between bud-scale disjunction and needle emergence (Desprez-Loustau \& Wagner, 1997). Phenological stage (using a 0-4 scale) was estimated at two different dates in 1998 and in 1999 before the inoculation of seedlings (Debazac, 1966). Each year, the phenological stage of each seedling was described by the mean value of the two observations (Phe98 and Phe99).

\section{Data analyses}

The s-PLUS ${ }^{\circledast} 2000$ package was used for basic statistical analysis.

The distribution of family means, at intra- and interpopulation levels, checked the underlying hypothesis of quantitative genetics for characters under polygenic control and allowed a quantitative approach in breeding for the traits studied.

A first multivariate mixed model nested ANOVA, was performed on a plot mean basis to test the presence of significant differences among populations and among families subordinated to populations. We decompose all the variates as follows:

$Y_{i j k}=\mu+B_{k}+P_{i}+F_{i j}+(B P)_{i k}+E_{i j k}$,

where $Y_{i j k}$ is the plot mean observation in the $j$ th family of the $i$ th population in the $k$ th block, $\mu$ is the overall mean, $B_{k}$ is the fixed block effect, $P_{i}$ is the fixed contribution for the $i$ th population with $i=1-3$ (families from Haguenau population, families from Taborz population and controlled-crosses from Haguenau $\times$ Taborz population), $F_{i j}$ is the random contribution for the $j$ th family of the $i$ th population with variance $\sigma_{F / P}^{2},(B P)_{i k}$ is the Block $\times$ Population interaction effect, and $E_{i j k}$ is the random between-plot error (block $\times$ family) with variance $\sigma_{\mathrm{e}}^{2}$.

(C) The Genetics Society of Great Britain, Heredity, 86, 36-44. 
In test $\mathrm{A}$, estimates of variance components were obtained using an analysis of individual trees of WP families from Haguenau and Taborz populations. The apparent purpose of the analysis of individual tree data is to provide estimates of variance within plots, which are necessary to calculate heritability on individual tree basis. This type of heritability is appropriate for estimating the genetic gain expected from mass selection even if common within-plot environmental effects might overestimate this parameter. A multivariate mixed model ANOVA and estimates of individual tree heritability were performed using the following linear model:

$Y_{i k l}=\mu+B_{k}+F_{i}+(B P)_{i k}+E_{i k l}$,

where $Y_{i k l}$ is the $l$ th individual observation in the $i$ th family of the $k$ th block, $\mu$ is the overall mean, $B_{k}$ is the fixed block effect, $F_{i}$ is the random effect of $i$ th family with variance $\sigma_{\mathrm{F}}^{2}(B F)_{i k}$ is the block $\times$ family interaction with variance $\sigma_{\mathrm{BF}}^{2}$, and $E_{i k l}$ is the random within-plot error with variance $\sigma_{\mathrm{w}}^{2}$.

The estimates of variance components for within-plot $\left(\sigma_{\mathrm{W}}^{2}\right)$, block $\times$ family $\left(\sigma_{\mathrm{BF}}^{2}\right)$, and family $\left(\sigma_{\mathrm{F}}^{2}\right)$ were obtained by the restricted maximum likelihood method. Assuming true half-sib families, the additive genetic variance within each population $\left(\sigma_{\mathrm{A}}^{2}\right)$ was estimated as $4 \sigma_{\mathrm{F}}^{2}$ for WP progenies. Thus individual tree narrowsense heritability $\left(h^{2}\right)$ was estimated as follows:

$\left.h^{2}=4 \sigma_{\mathrm{F}}^{2} / \sigma_{\mathrm{W}}^{2}+\sigma_{\mathrm{BF}}^{2}+\sigma_{\mathrm{F}}^{2}\right)$.

Standard errors of heritability estimates were estimated according to Falconer (1989).

In order to compare the relative amounts of withinpopulation genetic variation with different means, the additive genetic coefficient of variation (AGCV) was used (Cornelius, 1994). This coefficient was the square root of the additive genetic variance of a trait expressed as a percentage of the mean.

In tests $\mathrm{A}$ and $\mathrm{B}$, factorial and diallel analyses of variance were applied to plot means. Considering the small sizes of parental samplings, block and parental genotypes were treated as fixed effects according to the linear model:

$$
\begin{aligned}
Y_{i j k}= & \mu+B_{k}+\left[\mathrm{GCA}_{i}+\mathrm{GCA}_{j}\right]+\mathrm{SCA}_{i j} \\
& +\left[\left(B \cdot \mathrm{GCA}_{i k}\right)+\left(B \cdot \mathrm{GCA}_{j k}\right)\right]+E_{i j k}
\end{aligned}
$$

where $Y_{i j k}$ is the plot mean observation, $\mu$ is the overall mean, $B_{k}$ is the fixed block effect, $\mathrm{GCA}_{i}$ and $\mathrm{GCA}_{j}$ were the general combining ability of the $i$ th and the $j$ th parent, respectively, $\mathrm{SCA}_{i j}$ was the specific combining ability of this pair of parents $(i, j)(B . G C A)_{i k}$ and $(B . G C A)_{j k}$ were the interaction between the $k$ th block and GCA of the $i$ th and the $j$ th parent, respectively, and $E_{i j k}$ is the random between-plot error (block $\times \mathrm{FS}$ family) with variance $\sigma_{\mathrm{e}}^{2}$. For interpopulation crosses, the $i$ th and the $j$ th parent referred to the genotypes from Haguenau and Taborz origin, respectively.

By assuming the absence of any reciprocal effects, incomplete diallel analysis by Garretsen \& Keuls (1978) was used for the analysis of FS families from the Taborz population evaluated in test $\mathrm{A}$.

With respect to susceptibility traits observed and the sample sizes investigated, the phenotypic correlations are at least as good as estimators of the genetic correlations, as are the estimated genetic correlations themselves (Roff, 1995). The phenotypic correlation $\left(r_{\mathrm{p}}\right)$ is the standard Pearson product-moment correlation between the two phenotypic values of the traits.

\section{Results}

In this study, the inoculation of 1-year-old seedlings was carried out using an isolate of Melampsora pinitorqua considered to be heterogeneous with regard to virulence. In the greenhouse experiment, pine twist rust infected $96 \%$ of 2171 seedlings artificially inoculated in test A and $98.5 \%$ of 2010 seedlings in test B. Under these conditions, we consider the likelihood of disease escapes to be small, and that any seedlings that remained little infected were expressing resistance.

\section{Comparison of Scots pine population means}

In the analysis of variance, the mean square of familywithin-population was used as error to test for the statistical significance of the population effect. For all traits and tests, no significant block $\times$ population interaction was detected.

There were significant differences between populations (Haguenau, Taborz and hybrids Haguenau $\times$ Taborz) and highly significant effects of family-withinpopulation for rust susceptibility evaluated in tests A and $B$ (Table 2). FS families from Haguenau $\times$ Taborz crosses were highly susceptible to twist rust, close to the performance of families from Haguenau either in test A or in test B (Fig. 1). Families from Haguenau were more susceptible to twist rust than those from Taborz.

There were significant differences for shoot length among families-within-population in 1998 and 1999 $\left(F_{(57,393)}=2.17, \quad P<0.001 \quad\right.$ and $\quad F_{(61,242)}=11.14$, $P<0.001$, respectively) but intra-Taborz crosses showed significantly shortest elongation only in 1998 $\left(F_{(2,57)}=7.60, P<0.001\right)$. 
Table 2 ANova of rust susceptibility (Ndc and Psi) evaluated on plot means in 1998 and 1999 as a function of population and family within population

\begin{tabular}{|c|c|c|c|c|c|c|c|c|c|c|}
\hline \multirow[b]{2}{*}{ Source } & \multirow[b]{2}{*}{ d.f. } & \multicolumn{2}{|c|}{ Ndc98 } & \multicolumn{2}{|c|}{ Psi98 } & \multirow[b]{2}{*}{ d.f. } & \multicolumn{2}{|c|}{ Ndc99 } & \multicolumn{2}{|c|}{ Psi99 } \\
\hline & & MS & $F$ & MS & $F$ & & MS & $F$ & MS & $F$ \\
\hline Block & 7 & 5.06 & $34.12 * * *$ & 4.33 & $22.37 * * *$ & 4 & 0.28 & $2.21 \mathrm{NS}$ & 0.35 & $1.40 \mathrm{NS}$ \\
\hline Population & 2 & 7.28 & $11.37 * * *$ & 9.04 & $11.58 * * *$ & 2 & 3.70 & $4.87 *$ & 9.11 & $5.39 * *$ \\
\hline Family within population & 57 & 0.64 & $4.32 * * *$ & 0.78 & $4.03 * * *$ & 61 & 0.76 & $6.00 * * *$ & 1.69 & $6.66 * * *$ \\
\hline Block $\times$ population & 14 & 0.11 & $0.17 \mathrm{NS}$ & 0.25 & $0.31 \mathrm{NS}$ & 8 & 0.13 & $0.17 \mathrm{NS}$ & 0.39 & $0.23 \mathrm{NS}$ \\
\hline Error & 393 & 0.15 & & 0.19 & & 242 & 0.13 & & 0.25 & \\
\hline
\end{tabular}

NS, not significant; $* P<0.05 ; * * P<0.01 * * * P<0.001$.

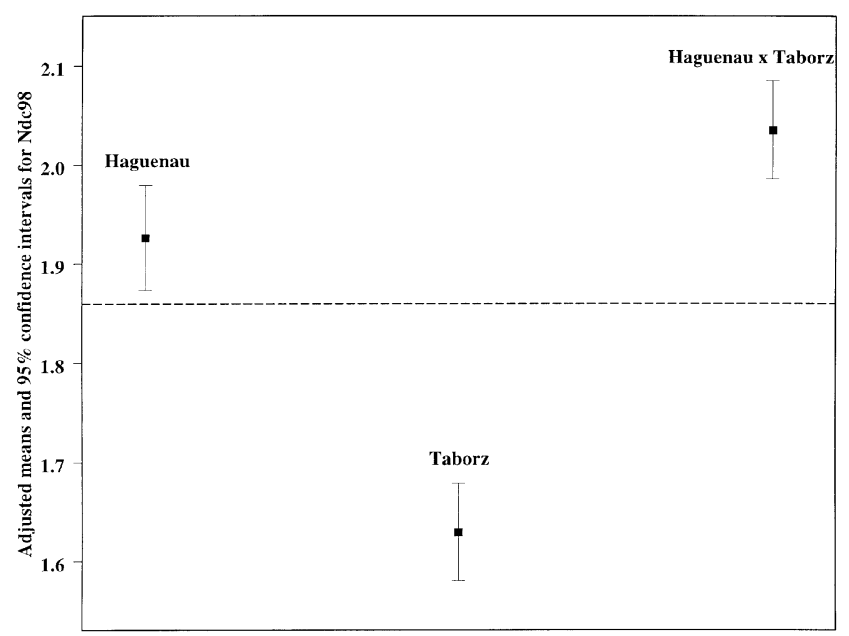

Fig. 1 Adjusted means for the severity of symptoms (Ndc) of WP and FS families from Haguenau and Taborz populations and hybrids evaluated in test $\mathrm{A}$. The dotted line pointed out the general mean for the trait.

Similarly significant family differences for phenological stage were observed in $1998 \quad\left(F_{(57,393)}=3.17\right.$, $P<0.001)$ and $1999\left(F_{(61,242)}=9.47, P<0.001\right)$ but intra-Taborz crosses were distinguished for late flushing only in $1998\left(F_{(2,57)}=18.64, P<0.001\right)$.

No significant phenotypic correlation was observed between shoot length, phenological stage and the two assessments of rust susceptibility in Taborz and Haguenau $\times$ Taborz crosses. However, in FS families from Haguenau, a slight negative relationship between shoot length and percentage of leader shoot surface covered by symptoms was observed in $1999\left(r_{\mathrm{p}}=-0.26\right.$, $P=0.004)$. In addition, later flushing phenotypes tended to be more rust susceptible in $1998\left(r_{\mathrm{p}}=-0.26\right.$, $P=0.03)$ and this negative relationship between phenological stage and percentage of leader shoot surface covered by symptoms was confirmed in 1999 $\left(r_{\mathrm{p}}=-0.33, P=0.003\right)$.

\section{Genetic variability among WP families of Haguenau and Taborz origin}

In the analysis of variance, the mean squares of block $\times$ family was used as error to test for the statistical significance of the family effect.

Within Haguenau and Taborz populations, WP families effect was highly significant for all traits (Table 3). The coefficient of additive genetic variation within the Haguenau population for pine twist rust susceptibility $(\mathrm{AGCV}=23.2 \%$ and $\mathrm{AGCV}=26.2 \%$, respectively, for $\mathrm{Ndc} 98$ and Psi98) was smaller than those estimated within Taborz population (AGCV = $36.9 \%$ and $\mathrm{AGCV}=36.9 \%$, respectively, for $\mathrm{Ndc} 98$ and Psi98).

Within the Taborz population, the narrow-sense heritability estimates for twist rust susceptibility were moderate but higher than those estimated within Haguenau (Table 4). The increased heritability in Taborz origin was caused primarily by an increase in the additive genetic variance with the phenotypic variance remaining more or less constant. Standard errors for heritabilities were generally high; thus the values of narrow-sense heritabilities estimated on a small number of families evaluated on multiple-tree plot should be interpreted with caution.

\section{Combining ability components in intra- and interpopulation crosses}

In tests $\mathrm{A}$ and $\mathrm{B}$, the diallel and factorial analyses indicated that GCA for rust susceptibility was found to be the major source of variation both in intra- and interpopulation crosses (Table 5).

Significant SCA effects for rust susceptibility were observed only in interpopulation crosses and in test B. Even in these cases, GCA effects remained predominant and family performances could be predicted with relative confidence by interpopulation GCA of both Haguenau and Taborz parents.

(C) The Genetics Society of Great Britain, Heredity, 86, 36-44. 
Table 3 AnOva of rust susceptibility evaluated on WP families from Haguenau and Taborz populations in 1998 as a function of family

\begin{tabular}{|c|c|c|c|c|c|}
\hline \multirow[b]{2}{*}{ Source } & \multirow[b]{2}{*}{ d.f. } & \multicolumn{2}{|c|}{ Ndc98 } & \multicolumn{2}{|c|}{ Psi98 } \\
\hline & & MS & $F$ & MS & $F$ \\
\hline \multicolumn{6}{|c|}{ WP from Haguenau } \\
\hline Block & 7 & 5.76 & $13.79 * * *$ & 4.32 & $7.80 * * *$ \\
\hline Family & 8 & 2.47 & $3.10^{* *}$ & 2.65 & $3.04 * *$ \\
\hline Block $\times$ Family & 55 & 0.80 & $1.91 * * *$ & 0.87 & $1.57 * *$ \\
\hline Error & 255 & 0.42 & 0.55 & & \\
\hline \multicolumn{6}{|l|}{ WP from Taborz } \\
\hline Block & 7 & 2.90 & $6.95^{* * *}$ & 4.81 & $10.31^{\text {*** }}$ \\
\hline Family & 10 & 3.20 & $4.95^{* * *}$ & 3.10 & $3.62 * * *$ \\
\hline Block $\times$ Family & 69 & 0.65 & $1.55^{* *}$ & 0.86 & $1.84 * * *$ \\
\hline Error & 278 & 0.42 & & 0.47 & \\
\hline
\end{tabular}

$* * P<0.01 * * * P<0.001$.
Table 4 Estimates of population mean, narrow-sense heritability $\left(h^{2}\right)$ and their associated standard error (SE), additive genetic variance $\left(\sigma_{\mathrm{A}}^{2}\right)$ and phenotypic variance $\left(\sigma_{\mathrm{P}}^{2}\right)$ for rust susceptibility evaluated on WP families from Haguenau and Taborz populations in 1998

\begin{tabular}{|c|c|c|c|c|c|}
\hline Traits & Mean & $h^{2}$ & $\mathrm{SE}$ & $\sigma_{\mathrm{A}}^{2}$ & $\sigma_{\mathrm{P}}^{2}$ \\
\hline \multicolumn{6}{|c|}{ Haguenau population } \\
\hline Ndc98 & 1.844 & 0.33 & 0.23 & 0.183 & 0.545 \\
\hline Psi98 & 1.702 & 0.30 & 0.21 & 0.199 & 0.672 \\
\hline \multicolumn{6}{|c|}{ Taborz population } \\
\hline Ndc98 & 1.474 & 0.54 & 0.20 & 0.297 & 0.546 \\
\hline Psi98 & 1.386 & 0.42 & 0.21 & 0.262 & 0.626 \\
\hline
\end{tabular}

Parent ranking for interpopulation GCA estimates for the two susceptibility traits corroborated parent ranking for intrapopulation GCA estimates (Fig. 2).

\section{Discussion}

\section{Differentiation of Scots pine populations for twist rust susceptibility}

In this study, large genetic variation within and between populations of Scots pine from Central Europe were observed for pine twist rust susceptibility. Genotypes from the Taborz population were late elongating and less susceptible to rust than those from the Haguenau population. The population ranking for growth, phenology of shoot elongation and rust susceptibility is in good agreement with performances observed on 3 -year-old seedlings after natural infection with the same inoculum source (Bastien \& Alia, 2000). In the same pathosystem under natural conditions, Andersson \& Danell (1997) found weak differences between northern Sweden and Finland populations but quite large genetic within-population variation.
Sinclair et al. (1999) showed, from mitochondrial DNA variation, that Scots pine populations from Poland and northern France (Haguenau) compose a north Central Europe evolutionary unit and suggested that these populations are closely related genetically. Nevertheless, clear East-West geographical trends were detected in the same species for adaptive traits such as survival, phenology of shoot elongation, frost tolerance and wood production traits (Giertych \& Oleksyn, 1992). Although empirical evidence concerning the potential interplay of the genetic structure of host and pathogen associations is very limited, the pathogen pressure may have influenced the genetic structure of host populations and lead to considerable host resistance in infested areas. Even though twist rust is endemic in the Haguenau population, no serious attack was reported in 20 years at this western limit of the natural range of Scots pine where the species is cultivated in even-aged pure stands. We hypothesize that unfavourable climatic conditions and/or the lack of the alternative host, namely Populus tremula, might not favour the development of all phases of the pathogen on both hosts. The low disease pressure could cause the population from Haguenau to develop a weak potential of resistance. In the mixed species Taborz forest, located in the centre of the natural range of Scots pine, high frequencies of twist rust attacks have been reported by Siwecki \& Chojnacki (1989) suggesting that aspens are abundant and inoculum is wind-dispersed on adjacent sites. Nevertheless insufficient information is available to permit direct comparison to be drawn between the genetic variation of Scots pine populations and the genetic structure of Melampsora pinitorqua isolates. Yang et al. (1997) have shown that provenances and families of Lodgepole pine (Pinus contorta Dougl. var. latifolia Engelm.) varied greatly in their response to western gall rust (Endocronartium harknessii) infection. This study also revealed several geographical clines of rust resistance in 
Table 5 Decomposition of GCA and SCA effects for rust susceptibility in intra- and interpopulation crosses evaluated on plot means in 1998 and 1999

\begin{tabular}{|c|c|c|c|c|c|c|c|c|c|c|}
\hline \multirow[b]{2}{*}{ Source } & \multirow[b]{2}{*}{ d.f. } & \multicolumn{2}{|c|}{ Ndc98 } & \multicolumn{2}{|c|}{ Psi98 } & \multirow[b]{2}{*}{ d.f. } & \multicolumn{2}{|c|}{ Ndc99 } & \multicolumn{2}{|c|}{ Psi99 } \\
\hline & & MS & $F$ & MS & $F$ & & MS & $F$ & MS & $F$ \\
\hline \multicolumn{11}{|l|}{ Within Haguenau origin } \\
\hline Block & 7 & 0.61 & $5.86 * * *$ & 1.33 & $7.60 * * *$ & 4 & 0.21 & $2.13 \mathrm{NS}$ & 0.09 & $0.48 \mathrm{NS}$ \\
\hline GCA & 4 & 0.10 & $0.94 \mathrm{NS}$ & 0.82 & $4.67 * *$ & 9 & 0.69 & $7.17 * * *$ & 2.11 & $11.85^{* * *}$ \\
\hline SCA & 4 & 0.18 & $1.74 \mathrm{NS}$ & 0.21 & $1.20 \mathrm{NS}$ & 13 & 0.08 & $0.80 \mathrm{NS}$ & 0.32 & $1.82 \mathrm{NS}$ \\
\hline Block $\times$ GCA & 28 & 0.09 & $0.90 \mathrm{NS}$ & 0.13 & $0.75 \mathrm{NS}$ & 36 & 0.15 & $1.52 \mathrm{NS}$ & 0.27 & $1.54 \mathrm{NS}$ \\
\hline Error & 28 & 0.10 & & 0.17 & & 52 & 0.10 & & 0.18 & \\
\hline \multicolumn{11}{|l|}{ Within Taborz origin } \\
\hline Block & 7 & 1.36 & $11.30 * * *$ & 0.49 & $3.18 * *$ & 4 & 0.07 & $0.80 \mathrm{NS}$ & 0.81 & $2.47 \mathrm{NS}$ \\
\hline GCA & 5 & 0.67 & $5.55 * * *$ & 0.20 & $1.31 \mathrm{NS}$ & 8 & 0.12 & 1.41 & 1.10 & $3.35^{* *}$ \\
\hline SCA & 4 & 0.23 & $1.93 \mathrm{NS}$ & 0.17 & $1.12 \mathrm{NS}$ & 7 & 0.10 & $1.21 \mathrm{NS}$ & 0.61 & $1.84 \mathrm{NS}$ \\
\hline Block $\times \mathrm{GCA}^{\mathrm{a}}$ & & & & & & 32 & 0.09 & $1.00 \mathrm{NS}$ & 0.27 & $0.81 \mathrm{NS}$ \\
\hline Error & 63 & 0.12 & & 0.16 & & 28 & 0.09 & & 0.33 & \\
\hline \multicolumn{11}{|l|}{ Within hybrids } \\
\hline Block & 7 & 1.97 & $17.44 * * *$ & 1.90 & $12.22 * * *$ & 4 & 0.10 & $0.61 \mathrm{NS}$ & 0.45 & $1.64 \mathrm{NS}$ \\
\hline Haguenau parent GCA & 5 & 1.18 & $10.46^{* * *}$ & 1.94 & $12.51 * * *$ & 4 & 3.01 & $18.88^{* * *}$ & 5.35 & $19.50 * * *$ \\
\hline Taborz parent GCA & 5 & 0.83 & $7.37 * * *$ & 0.68 & $4.36^{* *}$ & 4 & 0.67 & $4.22 * *$ & 2.72 & $9.90 * * *$ \\
\hline SCA & 10 & 0.17 & $1.54 \mathrm{NS}$ & 0.29 & $1.84 \mathrm{NS}$ & 7 & 0.33 & $2.05 \mathrm{NS}$ & 0.97 & $3.54 * *$ \\
\hline Block $\times$ GCA & 70 & 0.15 & $1.34 \mathrm{NS}$ & 0.21 & $1.38 \mathrm{NS}$ & 32 & 0.16 & $1.02 \mathrm{NS}$ & 0.27 & $1.00 \mathrm{NS}$ \\
\hline Error & 66 & 0.11 & & 0.16 & & 28 & 0.16 & & 0.27 & \\
\hline
\end{tabular}

NS, not significant; $* P<0.05 ; * * P<0.01 * * * P<0.001$.

${ }^{\mathrm{a}}$ In the diallel analysis of intra-Taborz crosses in test A, Block $\times$ GCA effects were confounded with error to respect calculation constraints.

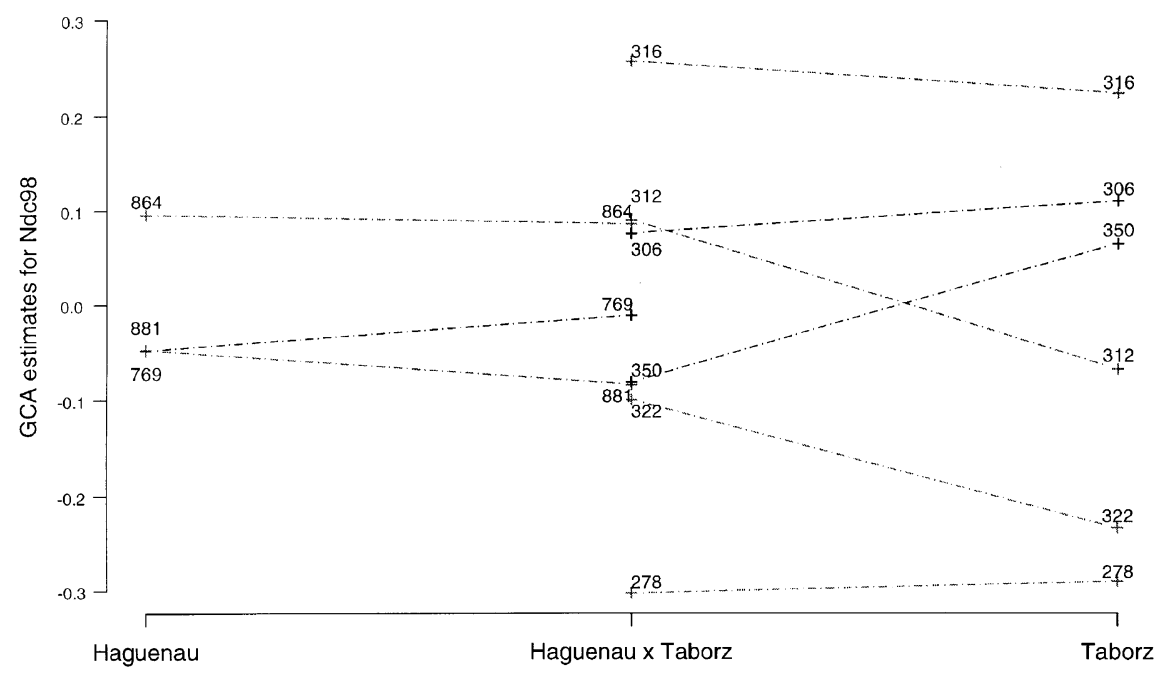

Fig. 2 Rank comparison of intra- and interpopulation GCA estimates for the severity of symptoms of three and six parents from Haguenau and Taborz popu- lations, respectively, observed in test A.
Lodgepole pine, suggesting that local adaptation could be important for the occurrence of clines.

Genetic specificity of the two natural populations, i.e. physiological mechanisms of resistance, or the influence of shoot length and/or phenological stage could also generate differences in rust susceptibility. However, no clear phenotypic correlation between the two traits could be observed in the two populations. Genetic correlations estimated with a large sample of genotypes from the two populations would help to clarify these relationships under natural conditions.

\section{Potential of intrapopulation recurrent selection}

Knowledge of the part of additive genetic variance within phenotypic variance is essential for predicting the 
effectiveness of intrapopulation recurrent selection and for determining appropriate breeding strategies. Although the Haguenau and Taborz populations displayed different susceptibility levels, the narrow-sense heritability estimates of susceptibility were moderately high and approximately of the same level in the two populations. Even if the narrow-sense heritability values of the present study could be inflated by the experimental design used, they surpassed the 0.08 and 0.18 values estimated by Andersson \& Danell (1997). These higher estimations could be explained by the high level of infection and better control of environmental variation provided by artificial resistance test (Dieters et al., 1996).

Major importance of additive genetic effects for twist rust susceptibility was confirmed by large differences in GCA estimates of the two sets of parents and nonsignificant SCA effects in controlled crosses. In earlier studies of the inheritance of fusiform rust resistance in slash and loblolly pines, Sluder (1988) and Griggs \& Walkinshaw (1982) showed highly significant variation in GCA for this trait and no significant variation in SCA. Because GCA effects were predominant, selection for reduced rust susceptibility based on WP or polycross progeny tests could be easily included in the management of the two existing breeding populations. The results provide support for using progeny tests of halfsib families, which require less effort and financial investment than diallel or factorial mating designs. The Haguenau breeding population could reasonably achieve the level of twist rust resistance found in the Taborz population by simple mass selection using a 15$20 \%$ selection intensity. Even if the Polish breeding population showed an acceptable level of susceptibility, about $30 \%$ genetic gain could be expected for this population from the same selection method. The multiple selection objectives of the Scots pine breeding programme will require revision in order to integrate possible antagonisms between volume production, stem form and disease resistance.

\section{Potential benefit of interpopulation hybridization}

From this first evaluation, interpopulation hybridization has failed to combine the reduced twist rust susceptibility of the Taborz parental population with the high susceptibility of the Haguenau population. Moreover, the susceptibility of Haguenau $\times$ Taborz hybrids reached the level of the most susceptible parental population, suggesting 'mean negative heterosis' between the two populations. Heterosis is usually explained by the presence of either directional dominance or overdominance gene action (Falconer, 1989). Van Der Kamp (1990) has shown that the qualitative nature of Scots pine resistance to western gall rust could be the consequence of several dominant genes for rust susceptibility. Moreover, the high susceptibility of hybrids has been observed in other forest tree-pathogen interactions (Roche \& Fritz, 1998). At this point, negative heterosis and its biological significance observed from the means must be distinguished from statistical GCA and SCA estimations. Absence of significant SCA effects for susceptibility and comparable ranking between intra- and interpopulation GCA estimations would allow confident prediction of hybrid performances by the mid-parent intrapopulation GCA values. However, confirmation is needed with a larger sample of parents from both populations. Absence of positive heterosis for twist rust would suggest that breeding efforts should be focused on recurrent selection within the two breeding populations.

\section{Acknowledgements}

We gratefully acknowledge many members of staff of INRA-Orleans for technical assistance. We thank S. Bussereau, A. Dowkiw and P. Vergnaud for participation in data collection and F. Lefèvre, M.-L. Loustau, F. Santi and S. Lee for their advice and helpful comments on the manuscript. We also thank the two anonymous reviewers for thoughtful comments on the manuscript.

\section{References}

ANDERSSON, B. AND DANELl, O. 1997. Is Pinus sylvestris resistance to pine twist rust associated with fitness costs or benefits? Evolution, 51, 1808-1814.

BARADAT, P. AND DESPREZ-LOUSTAU, M.-L. 1997. Analyse diallèle et intégration de la sensibilité à la rouille courbeuse dans le programme d'amélioration du pin maritime. Ann. Sci. For., 54, 83-106.

BASTIEN, C. AND ALIA, R. 2000. What might be useful measures of genetic variability for adaptative traits within populations of Scots pine? Invest. Agr. Sist. Recur. For., 1, 97-110.

BORATYNSKI, A. 1991. Range of natural distribution. In: Giertych, M. and Matyas, C. (eds) Genetics of Scots Pine, pp. 19-30. Elsevier, Amsterdam.

CORNELIUS, J. 1994. Heritabilities and additive genetic coefficients of variation in forest trees. Can. J. Forest Res., 24, 372-379.

DEBAZAC, E. F. 1966. Les modalités de la croissance en hauteur chez les pins. Bull. Soc. Bot. Fr., 113, 3-14.

DESPREZ-LOUSTAU, M.-L. 1986. Caractérisation morphologique et biologique des Melampsora spp. pathogènes des pins en Europe. Eur. J. Forest Path., 16, 360-374.

DESPREZ-LOUSTAU, M.-L. AND DUPUIS, F. 1994. Variation in the phenology of shoot elongation between geographic provenances of maritime pine (Pinus pinaster) - implications for the synchrony with the phenology of the twisting rust fungus, Melampsora pinitorqua. Ann. Sci. For., 51, 553-568. 
DESPREZ-LOUSTAU, M.-L. AND WAGNER, K. 1997. Components of maritime pine susceptibility to twisting rust - A path coefficient analysis. Eur. J. Plant Path., 103, 653-665.

Dieters, M. J., HODGe, G. R. AND White, T. L. 1996. Genetic parameter estimates for resistance to rust (Cronartium quercuum) infection from full-sib tests of Slash pine (Pinus elliottii), modelled as functions of rust incidence. Silvae Genet., 45, 235-242.

DINKINS, J. L. 1992. Field Test Design. In: Fins, L., Friedman, S. T. and Brotschol, J. V. (eds) Handbook of Quantitative Forest Genetics, pp. 96-139. Kluwer, Dordrecht.

FALCONER, D. S. 1989. Introduction to Quantitative Genetics, 3rd edn. Wiley, New York.

GARRETSEN, F. AND KEUlS, M. 1978. A general method for the analysis of genetic variation in complete and incomplete diallels and North Carolina II (NC II) designs. Part II. Procedures and general formulas for the fixed model. Euphytica, 27, 49-68.

GIERTYCH, M. AND OLEKSYN, J. 1992. Studies on genetic variation in Scots pine (Pinus sylvestris L.) coordinated by IUFRO. Silvae Genet., 41, 133-143.

GRIGGS, M. M. AND WALKINSHAw, C. H. 1982. Diallel analysis of genetic resistance to Cronartium quercuum $\mathrm{f}$. sp. fusiforme in Slash pine. Phytopathology, 72, 816-818.

HARFOUCHE, A., BARADAT, P. AND KREMER, A. 1995. Variabilité intraspécifique chez le pin maritime (Pinus pinaster Ait) dans le sud-est de la France. II. Hétérosis et combinaison de caractères chez les hybrides interraciaux. Ann. Sci. For., 52, 329-346.

HOLLIS, C. A., SMITH, W. H., SCHMIDT, R. A. AND PRITCHETT, W. L. 1975. Soil and tissue nutrients, soil drainage, fertilization and tree growth as related to fusiform rust incidence in slash pine. Forest Sci., 22, 141-148.

KLINGSTROM, A. 1963. Melampsora pinitorqua Rostr., pine twist rust. Stud. Forest. Suec., 6, 1-23.

KURKELA, T. 1973. Epiphytology of Melampsora rusts of Scots pine (Pinus sylvestris) and aspen (Populus tremula L.). Comm. Inst. For. Fenn., 79, 1-68.
MARTINSSON, O. 1980. Testing Scots pine for resistance to pine twist rust. Folia For., 422, 25-31.

MARTINSSON, O. 1987. Scots pine resistance to pine twist rust Conformity between the resistance found in an artificial environment and field trials. Silvae Genet., 36, 15-21.

OLD, K. M., LIBBY, W. J., RUSSEL, J. H. AND ELDRIDGE, K. G. 1986. Genetic variability in susceptibility of Pinus radiata to western gall rust. Silvae Genet., 35, 145-149.

ROCHE, B. M. AND FRITZ, R. S. 1998. Effects of host plant hybridization on resistance to willow leaf rust caused by Melampsora sp. Eur. J. Forest Path., 28, 259-270.

ROFF, D. A. 1995. The estimation of genetic correlation from phenotypic correlations: a test of Cheverud's conjecture. Heredity, 74, 481-490.

SINClAIR, W. T., MORMAN, J. D. AND ENNOS, R. A. 1999. The postglacial history of Scots pine (Pinus sylvestris L.) in western Europe: evidence from mitochondrial DNA variation. Mol. Ecol., 8, 83-88.

SIWECKI, R. AND CHOJNACKI, в. 1989. Epidemiology of Scots pine rusts in Poland. In: Hiratsuka, Y., Samoil, J. K., Blenis, P. V., Crane, P. E., Laishley, B. L. (eds) Proceedings of the IUFRO Rusts of Pine Working Party Conference, September 18-22, Banff, Alberta, Canada, pp. 158-162. Northwest Region, Forestry Canada.

SLUDER, E. R. 1988. Inheritance and gain in a half-diallel cross among Loblolly pines selected for resistance to fusiform rust. Silvae Genet., 37, 22-26.

STEPHAN, B. R. 1991. Inheritance of resistance to biotic factors. In: Giertych, M. and Matyas, C. (eds) Genetics of Scots Pine, pp. 205-218. Elsevier, Amsterdam.

VAN DER KAMP, B. J. 1990. Major gene resistance of Scots pine to western gall rust. Can. J. Forest Res., 21, 375-378.

YANG, R.-C., DHIR, N. K., YEH, F. C. AND HIRATSUKA, Y. 1997. Geographic variation in susceptibility of Alberta Lodgepole pine to western gall rust. Can. J. Forest Res., 27, 1398-1405. 